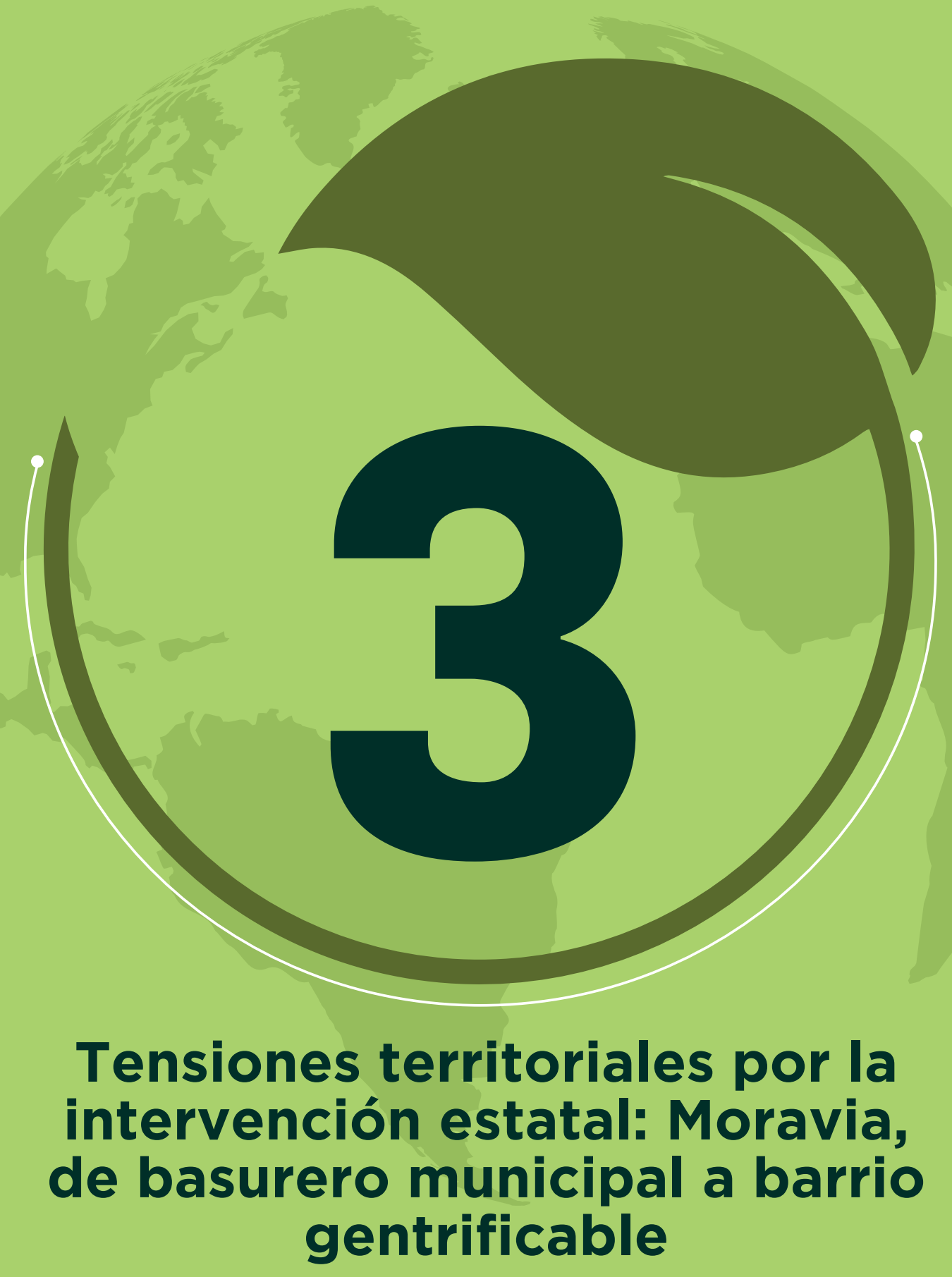



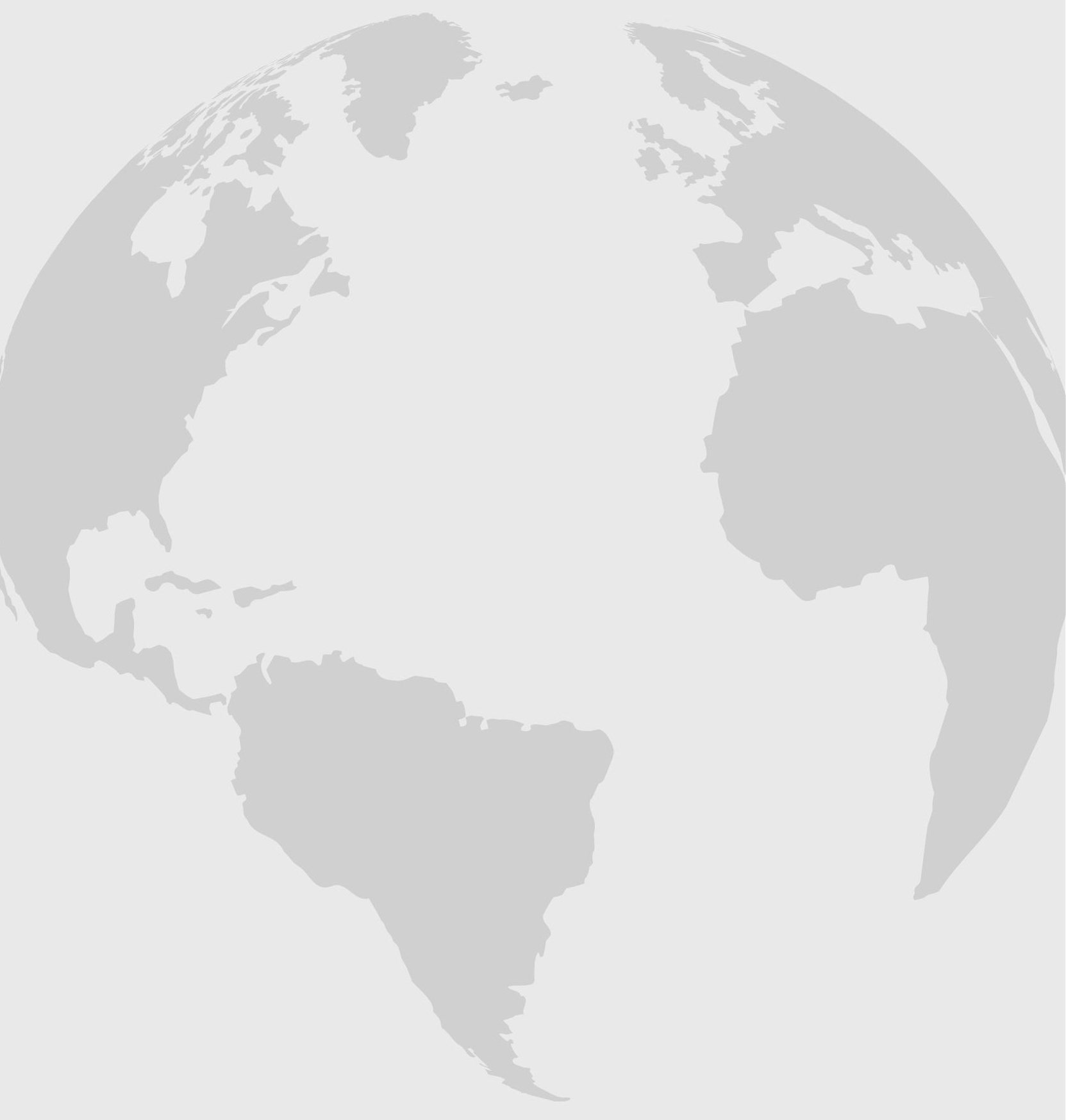


\section{Tensiones territoriales por la intervención estatal: Moravia, de basurero municipal a barrio gentrificable}

Hernán Pineda Gómez - Tecnológico de Antioquia hernan.pineda@tdea.edu.co

Jorge Montoya Restrepo - Tecnológico de Antioquia jmontoya@tdea.edu.co

Jordi Morató Farreras - Universidad Politécnica de Cataluña jordi.morato@upc.edu

\section{Introducción}

Las ciudades latinoamericanas están sufriendo verdaderos procesos de metamorfosis urbana como consecuencia de las nuevas dinámicas de circulación y espacialización del capital de forma desigual a su interior (Harvey, 2007; Lungo, 2005). Las intervenciones derivadas de este proceso tienen como característica que no se ejecutan en la totalidad del espacio urbano, por el contrario, el común denominador es ejecución por el desarrollo de grandes proyectos sobre fragmentos de la ciudad (Hidalgo y Janoschka, 2014; Lungo, 2005).

Esta forma de transformar los espacios urbanos está mediada por dos criterios que se entrelazan: 1. La intención de maximizar la tasa de ganancia a través de 
cambios en los usos del suelo, para obtener una mayor renta con ello (Vergara, 2013; Theodore et al., 2009, Lungo, 2005). 2. Grandes operaciones urbanísticas que tienen como fin "generar" fuentes de ventaja competitiva, que faciliten a las actividades económicas hegemónicas en las ciudades la inserción en circuitos globales. Su materialización lleva implícita la expulsión de un número importante de habitantes, los cuales no cuentan con una renta para solventar las valorizaciones que sobrevienen a partir de las intervenciones desarrolladas (Vergara, 2013). Esta forma de producir ciudad se configura como un reflejo del poder regulador y las nuevas disposiciones de funcionalidad institucional con el giro neoliberal (Lungo, 2005; Theodore et al., 2009).

Las discusiones teóricas y reflexiones empíricas alrededor de este fenómeno ponen de manifiesto dinámicas de segregación socioespacial, principalmente en las zonas céntricas de las ciudades de América Latina. Este proceso es facilitado por nuevas formas de gestión pública, como el empresarismo urbano, y en ellas, las administraciones públicas cumplen un rol importante al propiciar los procesos de gentrificación (Janoschka y Sequera, 2014; 2016) a partir de la adopción de políticas públicas que estimulan el mercado (Theodore et al., 2009).

En este contexto, la presente investigación analizó la configuración histórica del barrio Moravia de la ciudad de Medellín, Colombia, junto con las intervenciones estatales acontecidas -y en proyección- durante los últimos 40 años. La configuración y las características de este barrio, así como las operaciones urbanísticas trazadas, convierten a Moravia en un espacio permeable y propenso a la gentrificación. 


\section{Autoconstrucción barrial y transformaciones urbanas en contextos globalizados}

\section{Barrios autoconstruidos}

La construcción de gran parte de las ciudades latinoamericanas, incluyendo las ciudades colombianas, ha tenido un componente de urbanización informal y autoconstrucción. El desplazamiento masivo de habitantes del campo hacia las ciudades, tanto por olas de violencia como por el desarrollo industrial emergente en el siglo $\mathrm{XX}$, generaron un déficit habitacional (Alzate, 2014) que desbordó los modelos de ciudad formal trazados. ONU Hábitat (s. f.) calcula que Latinoamérica y el Caribe poseen en la actualidad entre 42 y 52 millones de viviendas precarias, siendo un fenómeno persistente. Si bien precariedad e informalidad no necesariamente expresan una relación directa, la capacidad de modificar los entornos informales sí depende de la capacidad adquisitiva de quienes allí residen (Torres, 2009), lo que agudiza el contexto de las nuevas periferias ante los procesos de renovación urbana y la búsqueda de captación de una mayor renta frente a nuevos usos.

Los nuevos pobladores urbanos - muchos despojados y desterrados - se vieron obligados a construir sus lugares de residencia alejados del centro de poder administrativo y político, y habitar en condiciones precarias con carencias de tierra, techo y trabajo (Torres, 2009). De esta forma, se erigieron en el espacio urbano dos ciudades paralelas: la formal, asociada a los planeadores y la informal, a la autogestión y la creatividad. En estas dos ciudades, en conflictividad y complemento, surgieron dos tipos de vivienda: la oficial y la informal. La primera de ellas ligada 


\section{sai}

al mercado y la formalidad institucional, la segunda, a la autogestión, la heterogeneidad, las disimilitudes en forma y apariencia y el trabajo colectivo (Sanín, 2009).

Las prácticas espaciales en los asentamientos informales y la forma urbana resultante no necesariamente implican caos o desorden. Por el contrario, sintetizan una forma particular de producción del espacio cuya característica central es la sumatoria de ausencia (ingresos estables, alimentación, servicios públicos, equipamientos, viviendas en condiciones dignas) y de formas de apropiación, ligadas a un gran arraigo (Torres, 2009), un reflejo de aspectos prácticos de la vida social. Desde esta perspectiva, la informalidad en la producción de ciudad presenta características ajenas a la planeación de la ciudad formal, porque no parte de la proyección comercial, el mercado o los planes de crecimiento de las ciudades, sino desde las condiciones y necesidades de quienes allí habitan. Para Torres (2009), la ciudad informal va de la mano de una economía informal, y afirma que son dos conceptos que deben ir unidos en los análisis.

Los barrios se van desarrollando de acuerdo con las posibilidades económicas, es decir, que entre menores sean los niveles de ingreso per cápita de los pobladores, tanto mayor serán los grados de hacinamiento y menor la calidad de vida que soporta. (p. 47)

Esta forma de producir ciudad está lejos de ser un fenómeno asociado al siglo XX. Por el contrario, las transformaciones urbanas de las ciudades en la actualidad aportan a la construcción de nueva informalidad urbana a partir de los procesos de expulsión de habitantes de los lugares que son intervenidos. Los nuevos usos pretendidos 
para estos espacios van asociados con una valorización que conlleva la expulsión de sectores poblacionales a las periferias, en condiciones de precariedad, porque allí se encuentran los terrenos que pueden pagar, ya sea en forma de alquiler o mediante nuevas formas de ocupación (De Mattos, 2009).

\section{Implicaciones espaciales de la globalización}

Janoschka y Sequera (2014) resaltan que una de las claves para comprender las transformaciones que "afectaron a las ciudades de América Latina en las últimas dos décadas ha consistido en la proliferación de políticas públicas que tienen el objetivo (explícito o implícito) de desplazar a las clases populares de las áreas centrales" (p. 82), lo cual implica la construcción de un modelo de ciudad restringido, centrado en la capacidad económica individual, que deja a merced del mercado a amplios sectores poblacionales con menores ingresos.

Las intervenciones desplegadas a partir de este tipo de políticas han adoptado como principio de acción la búsqueda de un "mayor y mejor uso", y están en la base de importantes decisiones de planificación, además, llevan implícita la búsqueda de mayor renta del suelo (Theodore et al., 2009; Vergara, 2013). Entre ellas se resalta la construcción de nuevos equipamientos, nuevas vías, nuevos espacios para el consumo y la atracción de capitales, renovación de los centros históricos, formación de nuevas centralidades, mejoramiento de zonas pobres, nuevos parques industriales, entre otros (De Mattos, 2009; Lungo, 2005; Theodore et al., 2009), que, en su conjunto, están reconfigurando las formas y usos en las ciudades. 


\section{Nuevas
90
PÁgina}

La intervención de amplias áreas urbanas, sobre todo en los centros de las ciudades, presenta como rasgo característico que se ejecuta en barrios con poca consolidación urbana o en condiciones de deterioro. Díaz (2013) cataloga este tipo de espacios como "propensos" a los procesos de transformación o espacios permeables. Estos espacios, por sus características de deterioro físico, social y de desvalorización de las viviendas, en contraste con su localización en zonas valorizadas o próximas a ellas, forman un escalón entre la renta de suelo capitalizada y la renta de suelo potencial, lo que motiva su intervención:

La primera se genera cuando un sitio o barrio, dado el actual uso de la tierra es capaz de producir una cierta cantidad de renta de suelo. Sin embargo, por su localización, esa zona podría generar aun mayor renta si tuviese un uso de suelo diferente. La renta potencial es la cantidad que podría ser capitalizada en virtud de un uso de suelo más intenso. (Smith, 1979; como se citó en Vergara, 2013, p. 224)

Esta operación convierte los espacios permeables en espacios propensos a la gentrificación, porque la posibilidad de captar mayor renta está mediada por la atracción de grupos de mayores ingresos a partir de nuevos usos (Vergara, 2013). Ruiz (2016) resalta que el proceso de desplazamiento urbano se da por el incremento generalizado de los precios del suelo, ya que parte de la población no se encuentra preparada para cubrir los nuevos costos de la tierra y las consecuencias económicas que esto acarrea, lo que origina la expulsión. Desde esta perspectiva, atraer nuevos residentes e inversionistas con mayor capacidad económica para un nuevo uso del suelo se ha convertido en la guía de los procesos de renovación y transformación del espacio urbano, y ello se ha constituido en un hilo conductor de los 
procesos contemporáneos de intervención en el espacio construido (Ruiz, 2016; Vergara, 2013).

\section{Acercamiento al fenómeno en América Latina}

En el ámbito regional, la informalidad resulta un fenómeno complejo, no sólo por la forma como se ha entendido, sus causas, sus dinámicas e implicaciones en los procesos de producción de ciudad, sino por cómo se ha intervenido. Fernández (2008) resalta que la experiencia acumulada en Latinoamérica a partir de sus programas de regularización ha sido un gran fracaso: no han logrado modificar las cifras y las condiciones en que se presentan. Por el contrario, desde los años noventa, el fenómeno de informalidad se ha agudizado.

Las nuevas intervenciones urbanas en diversas ciudades latinoamericanas, sobre todo en sus áreas centrales, han ampliado la expulsión de habitantes de territorios informales o en condiciones de deterioro ante un retorno al centro de ciertas actividades y habitantes asociados a nuevos usos y revalorizaciones (Vergara, 2013). Brites (2017) señala que desde los años noventa las ciudades latinoamericanas han sido objeto de políticas urbanas que inciden en la expulsión y generación de nuevos asentamientos informales. Esto ocurre, porque

Los megaproyectos revalorizan el suelo urbano, dando lugar a diversas formas de desplazamiento, desde el amedrentamiento legal y jurídico de los asentamientos informales (relocalización, remoción), hasta inéditas formas de desplazamiento vía elevación de los impuestos, presión inmobiliaria, cambios del entorno, pérdida de la identidad barrial, gentrificación, etc. (p. 583) 


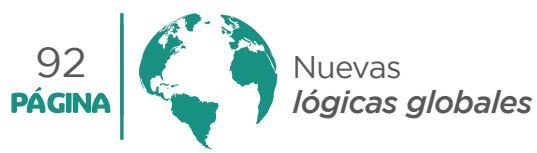

Estas acciones de renovación, lideradas por los entes públicos, se enmarcan en lo que se ha configurado como urbanización neoliberal (Brites, 2017; Theodore et al., 2009), en la que las políticas públicas se están utilizando para desplazar economías informales y facilitar el surgimiento de procesos de reproducción capitalista, especialmente en el sector inmobiliario formal (Janoschka y Sequera, 2014; 2016), ligados a "discursos 'empresariales' y representaciones enfocadas en la revitalización y rejuvenecimiento de las ciudades, y la reinversión en ellas" (Theodore et al., 2010, p. 10).

Lo anterior implica que en Latinoamérica las políticas de regularización, como la renovación urbana, no han logrado revertir la tendencia informal de amplios sectores urbanos, por el contrario, las nuevas intervenciones han generado un nuevo tipo de informalidad agudizada por la acción estatal para facilitar las intervenciones urbanas de gran magnitud y reconfigurar los espacios urbanos.

Este fenómeno se evidencia en el contexto de la ciudad de Medellín, donde las intervenciones trazadas en los planes de ordenamiento territorial, tanto en el formulado en 1999 como en su actualización en el año 2014, modificaron la apariencia, pero profundizaron la segregación (Gonzales, 2014).

\section{Metodología}

El diseño metodológico está centrado en el análisis territorial, el cual consiste en tres momentos entrelazados: 1. La revisión de las condiciones preexistentes y la especificidad del proceso acontecido; 2. Acciones y prácticas desarrolladas, en este sentido, se revisan las formas de ocupación e intervención en el área de estudio; 3. Se analizan las tensiones y efectos resultantes. Como 
técnica de indagación se utilizó la revisión documental. Cada fase del desarrollo investigativo aportó a la identificación de las conexiones entre las categorías definidas (autoconstrucción barrial, asentamiento informal e intervenciones urbanas en contexto globales) y su manifestación en el objeto de estudio.

El análisis se estructuró en fases. Primero se avanzó una revisión bibliográfica de la literatura relevante sobre debates y desarrollos conceptuales en torno a los procesos de autoconstrucción barrial e intervenciones estatales, en el marco de proyectos urbanos que apuntan a transformar el territorio mediante la atracción y retención de capitales; se hizo énfasis en cómo las nuevas intervenciones convierten estos espacios en propensos a la gentrificación. Posteriormente, se hizo la revisión documental sobre la historia del barrio Moravia, se describieron las principales características en su configuración; luego se analizaron las intervenciones estatales que se han proyectado para el barrio Moravia desde los años ochenta y los tratamientos y formas de ocupación en el nuevo Plan de Ordenamiento Territorial aprobado en el año 2014, con una visión de intervenciones al año 2030. A renglón seguido, el ejercicio de análisis documental se complementó con la revisión de la política de competitividad y su articulación con el ordenamiento territorial, con el fin de comprender cómo estas políticas no se limitan al desarrollo empresarial, por el contrario, están asociadas a formas y proyectos urbanos que llevan a procesos de revalorización de fragmentos de la ciudad. Finalmente, se procede al proceso de interpretación de la información, y se posibilita la discusión sobre las implicaciones del proceso de configuración e intervención adelantado en el barrio Moravia y su cualidad gentrificable. 


\section{Barrios autoconstruidos, el caso de Moravia}

Hablar de Moravia implica hablar de un territorio que se ha construido con el esfuerzo y tesón de sus habitantes, pero también desde el desdén institucional. Moravia se forjó en el límite del perímetro urbano municipal (década de los setenta), en las cercanías de la Universidad de Antioquia, el Jardín Botánico y el Parque Norte, en un terreno propiedad de la municipalidad (Torres, 2009) en paralelo con el río Medellín, para luego quedar incrustado en la zona céntrica de la ciudad (Comuna 4), producto del mismo crecimiento urbano.

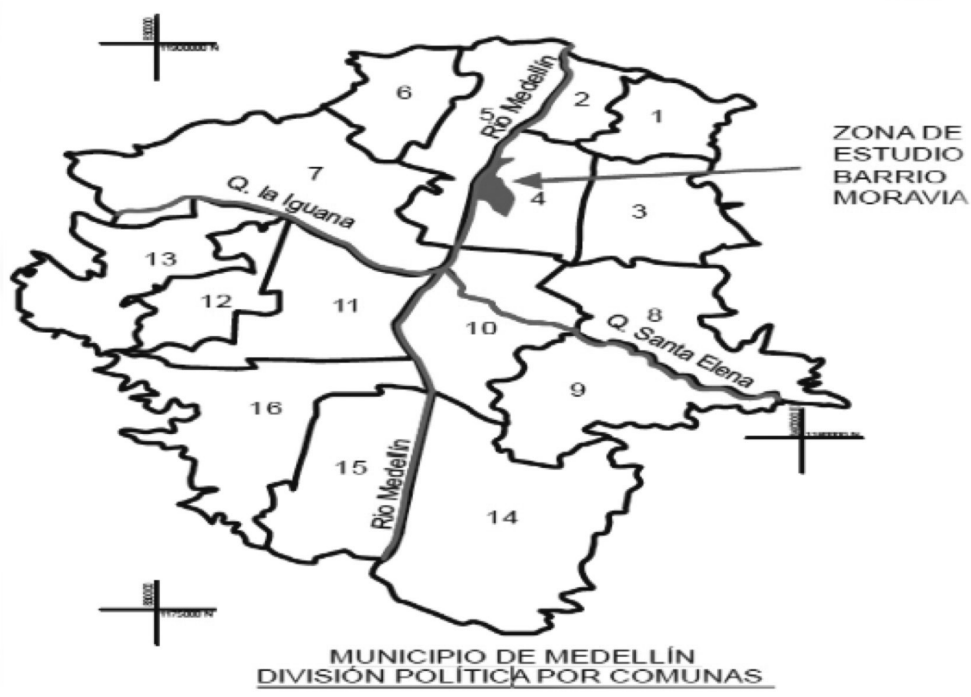

Figura 1. Barrio Moravia dentro de la ciudad de Medellín

Fuente: Sánchez (2010, p. 51).

Su poblamiento ha sido dinámico, a través de invasión y loteo; desde los años sesenta ya se encontraban en 
formación sectores como Fidel Castro, Moravia y El Bosque, pero se estima que el grueso de la población se asentó en la década de los ochenta (Torres, 2009). El proceso de ocupación se fue dando por sectores, empezando en lo que se denominaba Moravia y El Bosque, para luego seguir al sector de la Paralela del río o Llanito. Este barrio se fue convirtiendo en centro de atracción para pobladores sin vivienda en la ciudad (Santana, 1986).

A través de 25 años, se configuró en pleno centro de Medellín un vecindario completo sobre una montaña de basuras, constituido al margen de la planificación del Estado y de los ideales de progreso de la ciudad. Fue organizado gracias a los saberes tradicionales, el sentido común y la recursiva creatividad de sus habitantes, quienes mediante la autogestión y autoconstrucción dieron forma a un vecindario en cuyas viviendas los cánones e ideales de la arquitectura y la vida moderna se disolvieron casi por completo. (Sanín, 2009, p. 111)

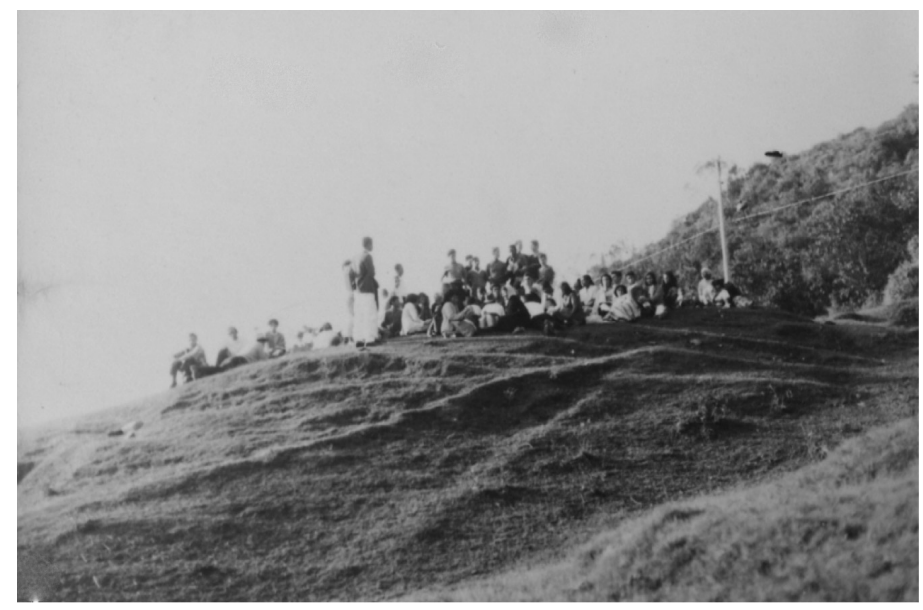

Figura 2. El Morro del barrio Moravia, antes de que fuera basurero municipal

Fuente: Archivo privado Colectivo Camilo Vive-Medellín. Foto: Giovanna Pezzotti. Licenciada bajo cc. Foto inédita, sin fecha. 


\section{$\begin{array}{lll}96 & \text { Nuevas } \\ \text { PÁgicas globales }\end{array}$}

Fueron múltiples los motivos que llevaron a sus pobladores a escoger este sitio como hábitat. La proximidad de este barrio a las estaciones del antiguo ferrocarril y la cercanía a la ribera del río Medellín le permitió a sus primeros habitantes extraer materiales para las viviendas o para la venta, así como la misma ubicación del basurero en este sector les posibilitó sobrevivir del reciclaje (Santana, 1986).

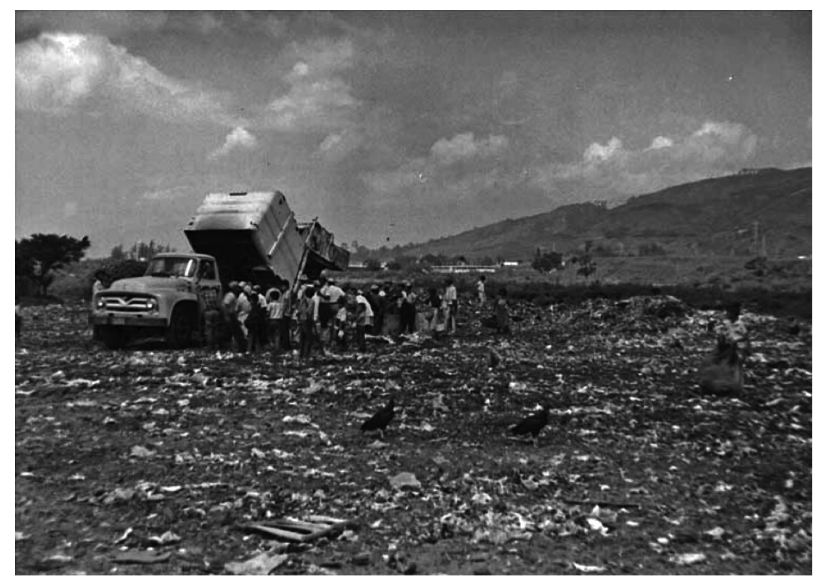

Figura 3. Basurero Municipal en el barrio Moravia

Fuente: Gabriel Carvajal (1964; como se citó en Calle, s. f.)

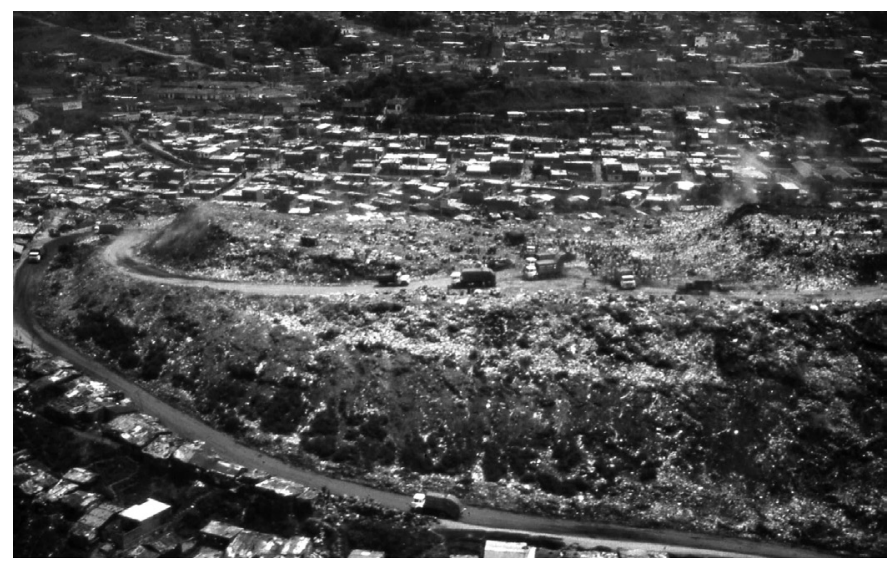

Figura 4. El basurero municipal, foto de los años ochenta

Fuente: Fotorreportaje sin autor. 
La estructuración del basurero, como punto de encuentro y poblamiento y su configuración como barrio, significó un sitio para la construcción de un hábitat, un espacio de resistencia y un lugar de lucha por una vivienda digna. De esta forma, Moravia se erigió como asentamiento informal cargado de un alto valor simbólico, de solidaridad, de organización y resistencia social:

La montaña constituyó un elemento integrador en cuanto permitió la conformación del barrio como tal, es decir, como compleja red de relaciones sociales con una estructura propia en la cual se han reforzado los vínculos por participación en las invasiones, en los enfrentamientos por el derecho a ocupar el espacio, y a la vivienda, por parentesco o paisanaje, por actividad (trabajo, estudio, autoempleo), etc. (CLEBA, 1987, p. 39)

Estas condiciones fueron dotando a Moravia a lo largo del tiempo de un repertorio amplio de relaciones sociales, las cuales han ido mucho más allá del basurero, las viviendas precarias y la informalidad de los asentamientos construidos. En este lugar, la organización comunitaria y el convite se configuran como elementos que anteceden y dan forma al asentamiento y a las dinámicas de resistencia y vida comunitaria, antes, durante y después de ser el sitio para el depósito de basuras en la ciudad, el cual operó allí formalmente entre finales de los años setenta e inicios de los ochenta. Varios autores destacan que el proceso de ocupación y poblamiento de este sector de la ciudad se entrelaza con un alto sentido comunitario y de organización social, lo que configura un tejido organizativo que se expresa en la conformación de juntas de acción comunal y el Comité de Tugurianos (Alzate, 2014; CLEBA, 1987; Santana, 1986). Las formas organizativas y las 


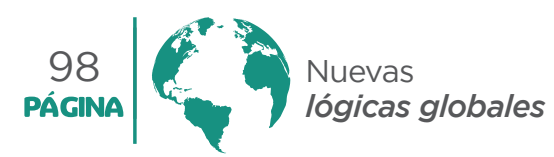

acciones impulsadas por ellas surgen desde el primer momento como respuesta a los intentos de desalojo direccionados por la administración municipal -elemento recurrente en el periodo de estudio-, pero también como acción para la dotación de servicios públicos y el mejoramiento barrial (CLEBA, 1987). De esta forma, el proceso de ocupación en Moravia se da en tensión con las proyecciones de recuperación del predio por el ente municipal, lo que marcaría un proceso turbulento frente a las apuestas institucionales por imponer allí unos usos diferentes del suelo.

A lo largo de los años, este sector pasó de ser el basurero municipal barrio reconocido por la institucionalidad con la formalidad de la legalización. Sin embargo, la transformación del espacio construido ha sido un proceso lento, pues todavía existen fragmentos que no han superado las condiciones de su surgimiento (Alzate, 2014; Torres, 2009), donde el rebusque y las precariedades económicas siguen estando presentes.

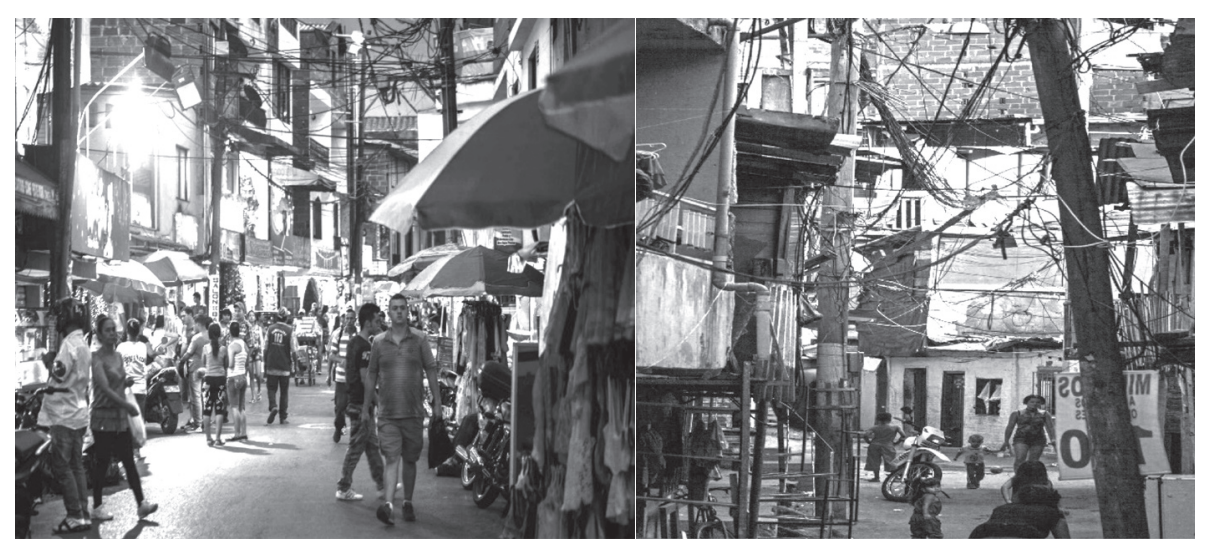

Figura 5. La cotidianidad y forma actual en Moravia

Fuente: Calle (s. f.) 


\section{Intervención estatal en Moravia}

Durante los últimos 40 años, en Moravia se han proyectado -aunque no siempre ejecutado- una serie de intervenciones lideradas por el Municipio, las cuales han oscilado entre recuperar el antiguo predio municipal, generar condiciones de habitabilidad, mitigar el impacto ambiental del antiguo basurero, y generar equipamientos públicos a partir de tratamientos urbanísticos como el mejoramiento integral barrial y, más recientemente, iniciativas de renovación urbana de acuerdo con la proyección de la zona céntrica de la ciudad como atractivo competitivo. Esta ambivalencia en la acción institucional ha propiciado una fricción permanente por el uso del espacio, donde las iniciativas públicas en múltiples ocasiones han significado la expulsión de habitantes de Moravia. Las distintas iniciativas adelantadas se pueden sintetizar en cinco etapas:

- La primera entre 1984 y 1988 con el Programa de Rehabilitación del antiguo basurero.

- La segunda etapa entre 1994 y 1997 con el Plan de Desarrollo y Convivencia de Moravia, pero que se venía planteando desde inicios de 1990 a raíz del conflicto urbano que se estaba viviendo.

- La tercera se plantea en 1999 con el proyecto "Estudios y diseños para la formulación del plan parcial del macroproyecto mejoramiento integral del barrio Moravia".

- La cuarta fue el Plan Parcial de Mejoramiento Integral del Barrio Moravia, formulado entre 2002 y 2004 por la Escuela de Urbanismo de la Facultad de Arquitectura de la Universidad Nacional de Colombia - sede Medellín (Gonzales, 2011).

- La última etapa de intervenciones se encuentra en el Plan de Ordenamiento Territorial de Medellín, aprobado 


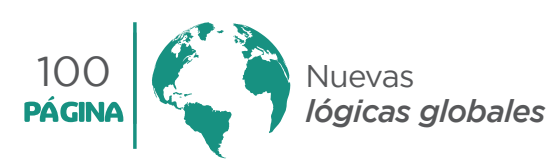

mediante el Acuerdo Municipal 048 de 2014, donde se proyecta en Moravia un tratamiento de renovación urbana y un modelo particular de ocupación del espacio.

\section{El programa de rehabilitación del antiguo basurero (1984-1986)}

Cerrado el basurero municipal en 1982, la Alcaldía de Medellín promovió lo que se conoce como el Programa de Rehabilitación. Este programa se centró en una reforma urbana para la legalización del sector, construcción de infraestructura para servicios y obras para la canalización de quebradas, adecuación de senderos y vías de acceso. El resultado de las intervenciones trazadas fue un reordenamiento urbanístico, la restructuración de predios, parte de un plan vial (parcialmente las vías de acceso) y equipamientos básicos (escuelas, centro de salud, casa comunal). Pero también está reseñado que el proceso de intervención generó choques con la comunidad en relación con la legalización de predios y la falta de intervención del cerro de basuras (Gonzales, 2011), elemento que se convirtió en factor de fricción y disputa política entre la municipalidad y los habitantes de Moravia:

Una de las fallas del Programa de Rehabilitación fue no reconocer los problemas comunes que afectaban a la población - pobreza, desempleo, insalubridad, falta de servicios públicos, mal alojamiento, entre otros-, "desconociendo" las particularidades de algunos sectores que componían a la "comunidad. ... la existencia de viviendas ocupadas por varias familias, sobre todo en los sectores más pauperizados como El Bosque y Llanitos, no contó con una solución que pusiera fin al hacinamiento. Por otra parte, las familias que habitaban los 
denominados tugurios, ubicados sobre todo en El Bosque, Llanos, Llanitos y El Morro, no tuvieron una solución de vivienda, ni les fueron otorgados gratuitamente - teniendo en cuenta su condición socioeconómica- materiales para mejorarlas por su cuenta, pues el programa no consideró este punto, pese a que cerca de la mitad de la población total del área vivía en estas condiciones. (Alzate, 2014, p. 205)

Alzate (2014) destaca que entre las proyecciones trazadas por la acción institucional se encontraba la reubicación de vivienda en el sector La Milagrosa, Comuna 8 de la ciudad, sector distante de Moravia, acción que no representaba las demandas de la comunidad y además implicaba un proceso de expulsión y ruptura de relaciones construidas. Esta primera intervención, junto a las acciones adelantadas por la institucionalidad en el periodo de estudio, marcó una línea que se conservaría en las futuras intervenciones, signada por la desconexión entre los reclamos de los habitantes y las apuestas de la institucionalidad. Por ello las fallas descritas en un programa de los años ochenta se siguieron repitiendo en las futuras intervenciones municipales.

\section{Plan de desarrollo y convivencia de Moravia 1994-1997}

Este plan surgió en un contexto de fuerte violencia en la ciudad de Medellín, como iniciativa de la Mesa de Trabajo por la Paz y la Convivencia "José Hernán Ramírez", acompañada por el Instituto Popular de Capacitación (IPC) y el ente municipal: 
El plan comprometía el concurso del gobierno local para retomar los compromisos adquiridos desde el programa de rehabilitación, como el tratamiento de la montaña de basuras y la legalización para concretar el reordenamiento urbano y el saneamiento jurídico de los predios. (Departamento Administrativo de Planeación, 2006, p. 4)

Esta propuesta buscó retomar las promesas incumplidas 12 años atrás - una constante de las intervenciones- en el Programa de Rehabilitación del basurero municipal y se convirtió en insumo para la formulación de las etapas tres y cuatro de este nuevo plan; pero el contexto de violencia en la época lo dejó sólo en una intencionalidad, sin que hubiera tenido algún tipo de desarrollo (González, 2011).

\section{Plan parcial de mejoramiento integral del barrio Moravia, Decreto 1598 de 2006}

En 1999 fue aprobado el Acuerdo municipal 062, por medio del cual se adopta el primer plan de ordenamiento territorial para la ciudad de Medellín. En este plan se define el Mejoramiento Integral Barrial para los polígonos del barrio Moravia, tratamiento urbanístico cuyo fin era mejorar las condiciones físicas y de infraestructura, buscando corregir los grados de deterioro físico y ambiental presentes. 

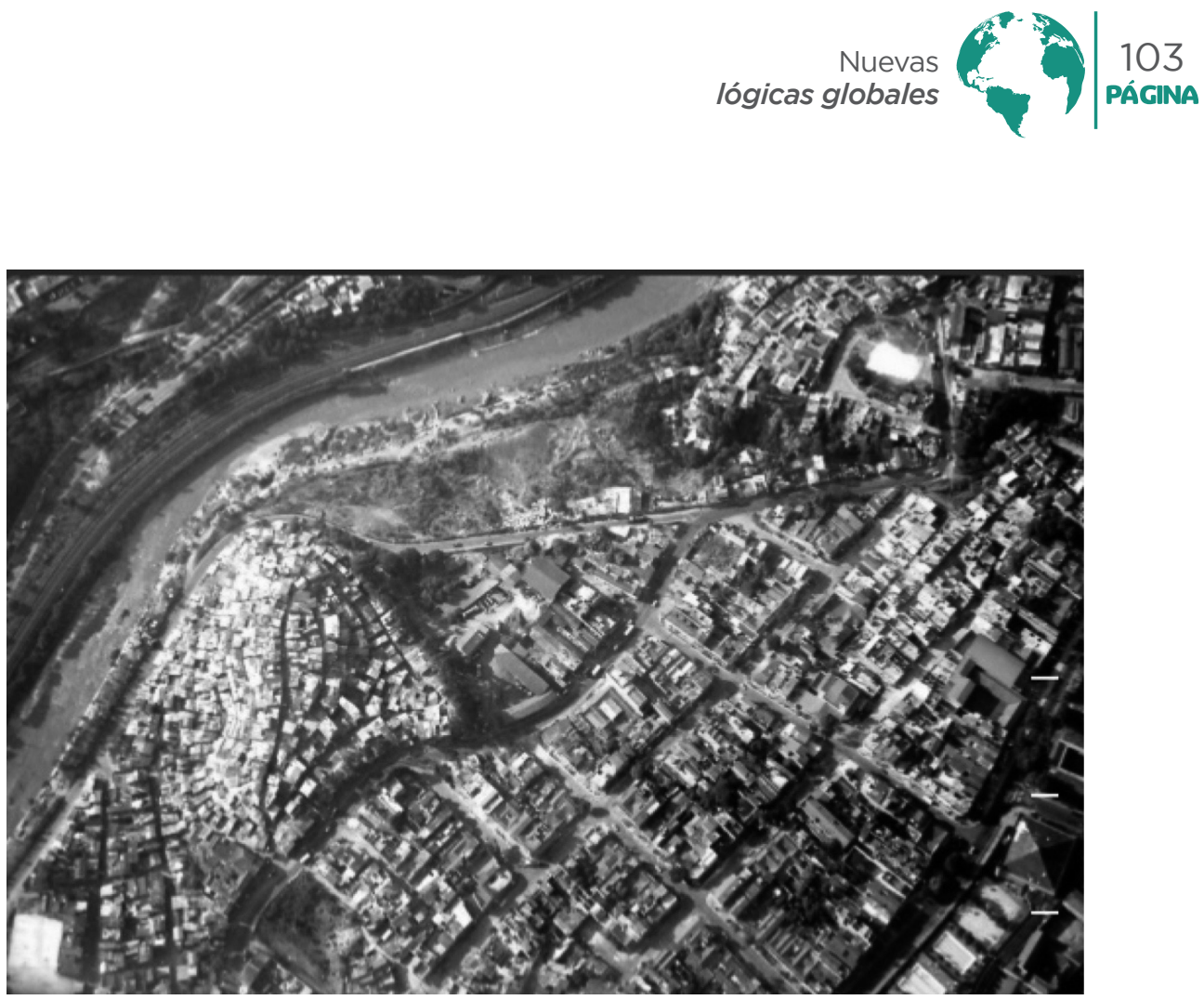

Figura 6. Estructura del barrio Moravia para el año 2004

Fuente: Concejo de Medellín (2015, p. 10)

Para el año 2004, las condiciones paisajísticas de Moravia habían sido modificadas parcialmente (Figura 6), ya no era tan evidente su pasado como basurero, pero se mantenían sectores con poca o nula consolidación urbana. Sin embargo, un estudio de monitoreo de lixiviados y gases en el sector de Moravia, realizado por la Universidad de Antioquia, concluyó que "la población que habita en el morro de Moravia, ha estado sometida a un elevado riesgo químico, ya que la zona no cuenta con las mínimas condiciones ambientales y de salubridad para ser habitada" (ACI Medellín-Consorcio UdeA-UPC-CSIC, 2007, p. 3), y emitió una alerta por el inminente riesgo ambiental. De allí que el Plan de Mejoramiento de Moravia de la época haya planteado reasentar a familias localizadas en zonas de alto riesgo no recuperable como el Morro de Basuras, el Oasis Tropical y la Herradura (Uribe, 2010). 


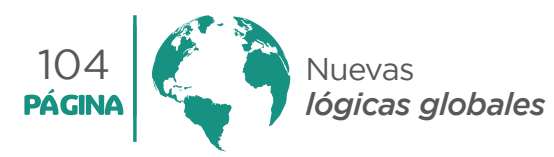

Según el censo de 2004, año en el que se define el "Proyecto de Intervención Integral de Moravia y su área de influencia” y base del plan parcial, 2.224 familias se alojaban en sus 10 hectáreas de terreno, sobre una montaña de 35 metros de altura conformada por 1,5 millones de toneladas de desechos. La inestabilidad del suelo, sus altas pendientes, la fragilidad de las construcciones, la presencia de desechos industriales, clínicos y domésticos y la continua emanación de gases tóxicos y lixiviados, hacía que los habitantes de Moravia estuvieran sometidos a un elevado riesgo químico y microbiológico, lo que hizo que fuera declarada la emergencia ambiental en el año 2006. (Montoya et al., 2011, p. 4)

Sin desconocer su importancia para mejorar las condiciones de habitabilidad de un grupo importante de familias y para la recuperación ambiental de un sector de la ciudad (Montoya y Pineda, 2018), de este plan es necesario resaltar dos elementos. En primer lugar, se repitieron las fricciones entre el Estado y los habitantes por los procesos de reubicación y los mismos procesos de destrucción de los ranchos ubicados en El Morro y el Oasis. En segundo lugar, el traslado de habitantes para la Ciudadela Nuevo Occidente, en la periferia de Medellín, que tenían sus fuentes de ingresos en la actividad informal que giraba en torno al reciclaje y en el centro de la ciudad, les generó un nuevo problema: el costo de desplazamiento entre el lugar donde desarrollaban las actividades informales y el de residencia. Nuevamente, se dio un proceso de reasentamiento distante del lugar de construcción social y se repitió un eje articular de las acciones institucionales, esto es, los problemas cotidianos de los habitantes que vivían el impacto de la intervención no tuvieron protagonismo en el diseño del plan, y 
emergieron una serie de conflictos durante el periodo (Mesa interbarrial, s. f.).

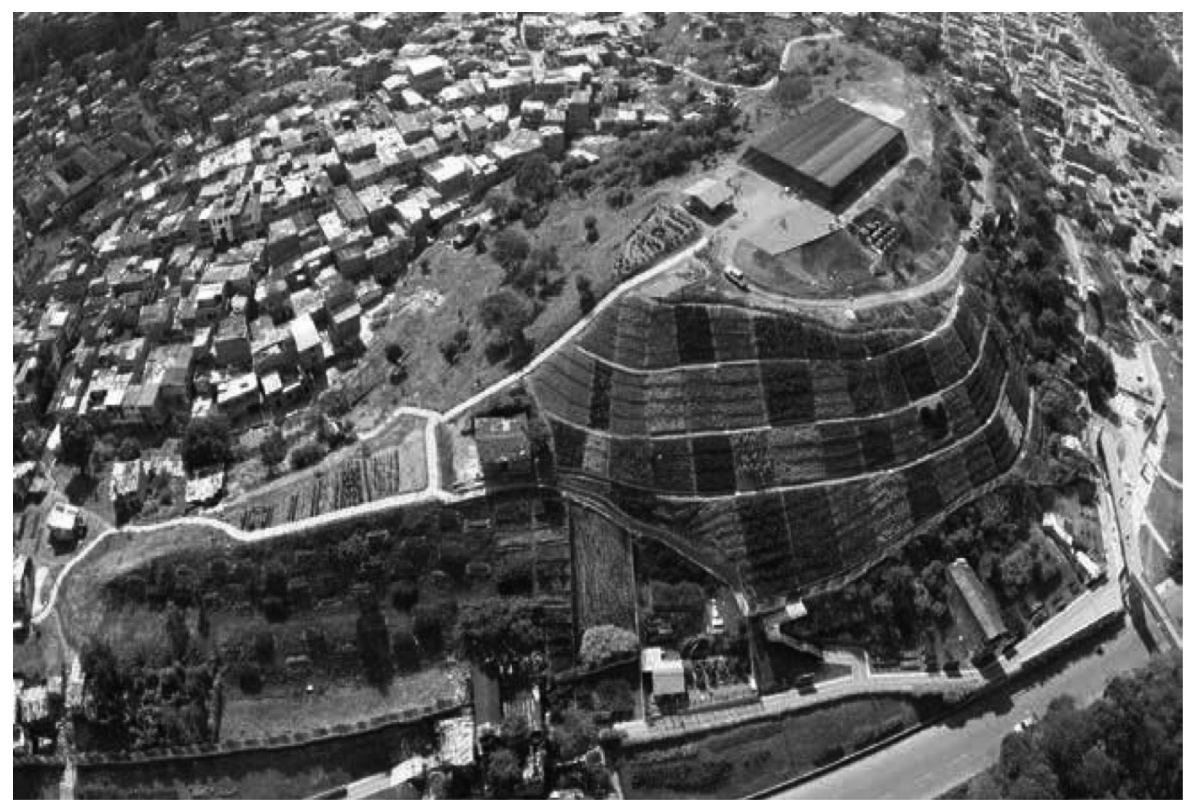

Figura 7. Intervención ambiental en el antiguo basurero municipal-barrio Moravia

Fuente: Alcaldía de Medellín (2014a, p. 81)

\section{Plan de Ordenamiento Territorial (POT) de Medellín 2014-2030}

En el año 2014, el Concejo Municipal de Medellín aprobó el Acuerdo 048, por medio del cual se adoptó el Plan de Ordenamiento Territorial con una proyección de transformación para la ciudad al 2030, en donde el corredor del río -que recorre de sur a norte toda la ciudad y que pasa paralelo a Moravia - se convirtió en un escenario de intervención estatal de orden estratégico a partir de procesos de renovación urbana, lo que implicaba la transformación de sectores tradicionales de la ciudad. 
Uno de los polígonos seleccionados para este tipo de tratamiento es el Z1_R_7, el cual corresponde al barrio Moravia, con un área correspondiente a 46,894 Ha, siendo una de las mayores áreas de renovación proyectadas en el nuevo POT. Es de resaltar que esta actualización del POT modificó el tratamiento de intervención que había sido estipulado para el barrio Moravia en el año 1999, el cual pasó de Mejoramiento Integral Barrial a Renovación Urbana, lo cual implica un cambio notable en las proyecciones de intervención y apuestas de nuevos equipamientos, así como en los usos y en la nueva infraestructura en el sector. La modificación del tipo de tratamiento indica que este fragmento de ciudad sufrirá una transformación radical, donde se buscará que el potencial de uso esté en concordancia con el proceso de transformación que se adelanta en el centro de la ciudad. Este elemento se observa en el documento técnico de intervención del Plan parcial de Moravia, adoptado mediante Decreto municipal 0321 del 29 de mayo de 2018, en donde se perfilan las unidades de actuación y los desarrollos habitacionales que se llevarían a cabo en esta zona de la ciudad.

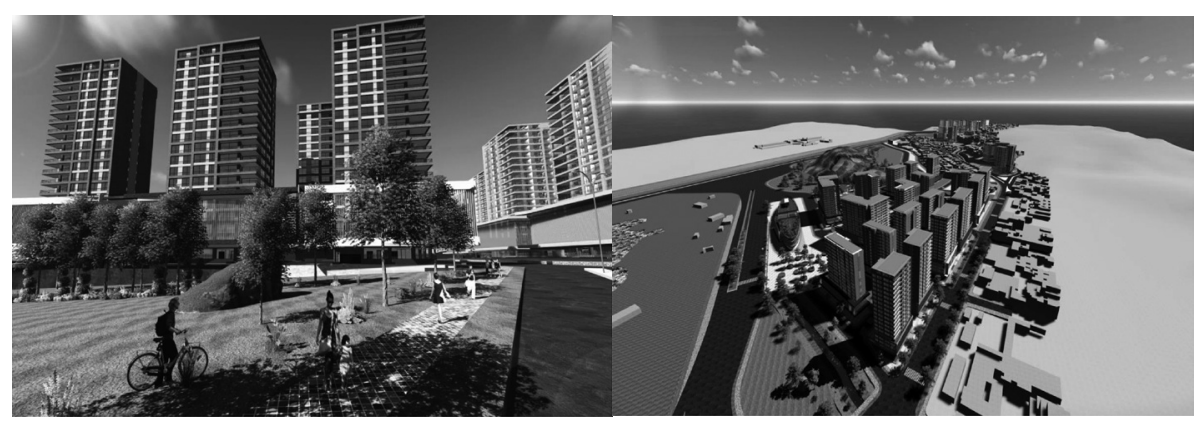

Figura 8. Proyección del espacio público y desarrollos habitacionales en Moravia de acuerdo con el POT 2014-2030

Fuente: Alcaldía de Medellín (2018, pp. 155 y 244) 


\section{Competitividad, transformación del centro ampliado de Medellín y su incidencia en Moravia}

El modelo de ciudad asociado a las intervenciones implementadas y en proyección para el caso de la ciudad de Medellín, está relacionado con la formación de clústeres estratégicos, los cuales se enmarcan en la política de ciudad clúster, definida en el año 2009 a través del Acuerdo 087 del Concejo Municipal, que la convierte en política pública, pero cuyos orígenes se remontan a mediados de la década de los noventa con el estudio denominado "Estudio Monitor: la ventaja competitiva de Medellín".

El discurso y las intervenciones urbanas asociados al modelo clúster se encuentran ligados a intervenciones en los flujos de movilidad y renovación del centro ampliado de la ciudad como elemento que permite generar ventaja competitiva (Pineda, 2019). Por ello las nuevas proyecciones de intervención, tanto en Moravia como en el centro ampliado y representativo de la ciudad de Medellín para los próximos años, se enmarcan en apuestas de infraestructuras complementarias a la competitividad. Igualmente, la administración municipal viene incentivando el asentamiento de las empresas que integran los clústeres en la zona norte de la ciudad, específicamente en los polígonos ubicados en los barrios Jesús Nazareno, Sevilla y Chagualo, barrios aledaños al barrio Moravia, a partir de la generación de incentivos tributarios a las empresas que evidencien innovación en productos, procesos o servicios. Esta iniciativa se encuentra enmarcada en la construcción del Distrito de la Innovación (Figura 12), contemplada en el artículo 62 del Acuerdo municipal 048 de 2014.

Desde esta perspectiva, cobran relevancia los nuevos usos que se proyectan en el nuevo POT, el cual plantea una 
serie de intervenciones con tratamiento de renovación urbana en el eje estructurante del río Medellín, que se representan en color rosado en la Figura 9.

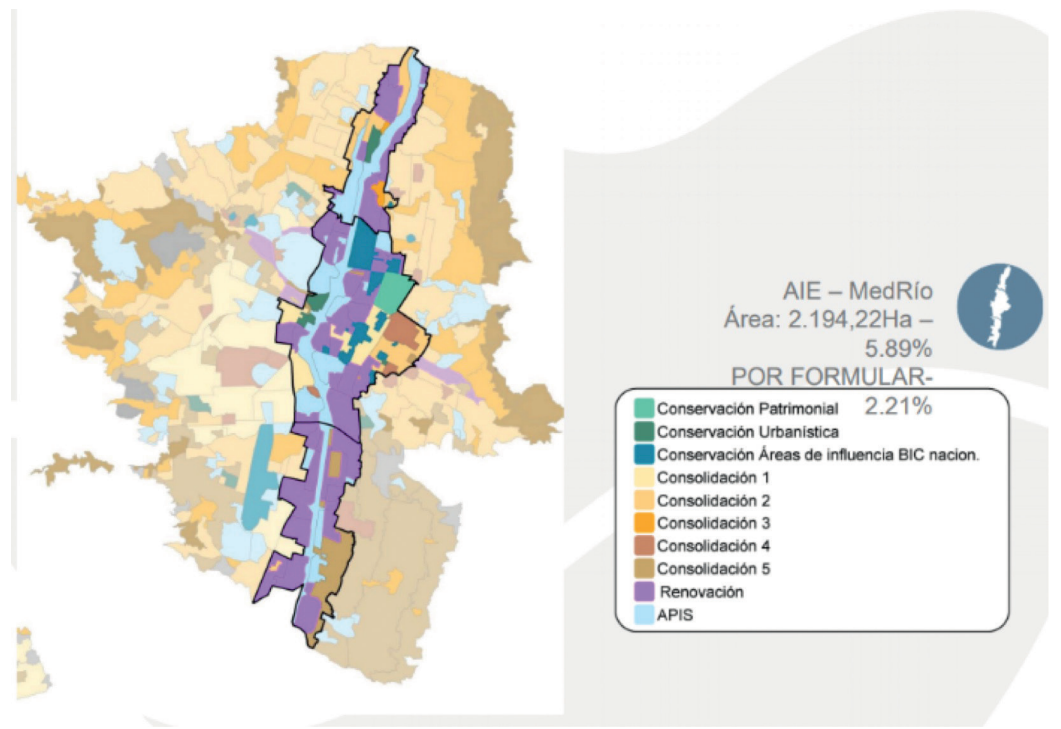

Figura 9. Tratamientos a los polígonos de intervención Macroproyecto Medrío

Fuente: Departamento Administrativo de Planeación (s. f., p. 11)

La apuesta del modelo de ciudad al 2030 que traza el POT pretende desarrollarse a partir de grandes operaciones urbanas denominadas macroproyectos, diez en total. De estos, tres se desarrollarán en el sector céntrico, denominado Medrío y que corresponden al polígono delimitado en la Figura 9; cinco macroproyectos para ejecutar en el sector de bordes, y dos macroproyectos denominados transversales ${ }^{1}$.

1 Para mayor información, consultar áreas de intervención estratégicas de Medellín: https:// www.medellin.gov.co/ irj/ go/ km/docs/ pccdesign/ Subportal del Ciudadano_2/ Plan de Desarrollo_0_17/ Programas y Proyectos/ Shared\%20Content/Documentos/2015/Macroproyectos\%20 POT/ Taller\% 201\% 20-\% 20Oficial\% 20Río Centro\% 20-\% 2011ago15\% 20 (DAPM).pdf 
El área estratégica denominada Medrío agrupa los macroproyectos Río Sur, Río Norte y Río Centro, este último dividido en tres subsectores: subzonas Centro Tradicional, Río Centro y Distrito de Innovación (Figuras 10 y 11). En estas apuestas de intervención, el barrio Moravia limita con las intervenciones proyectadas en Río Norte y hacia el sur, específicamente con las subzonas Río Centro y Distrito de Innovación, lo que genera una tensión por los usos del suelo, sobre todo si se tiene en cuenta que para este barrio se proyecta tratamiento de renovación urbana.

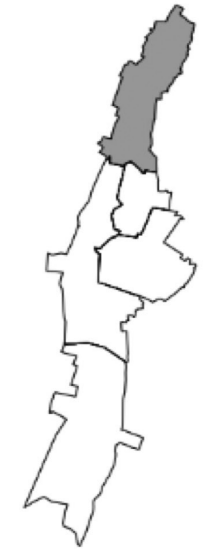

AIE - RIO NORTE

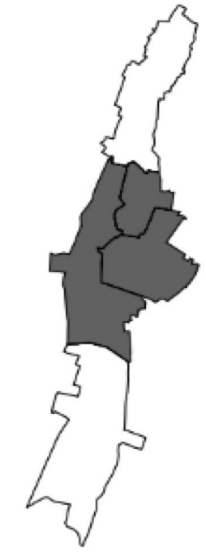

AIE - RIOO CENTRO

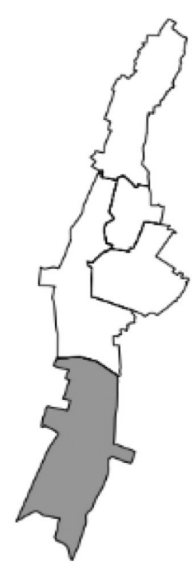

AIE - RIOO SUR

Figura 10. Área de intervención estrategia Medrío

Fuente: Alcaldía (2014a, p. 8) 


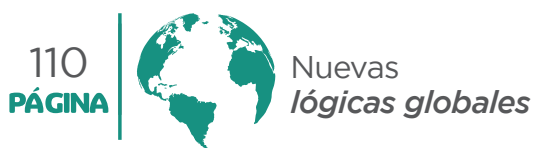

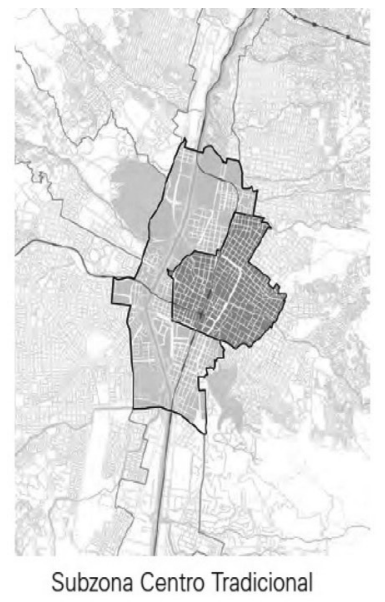

Subzona Centro Tradicional
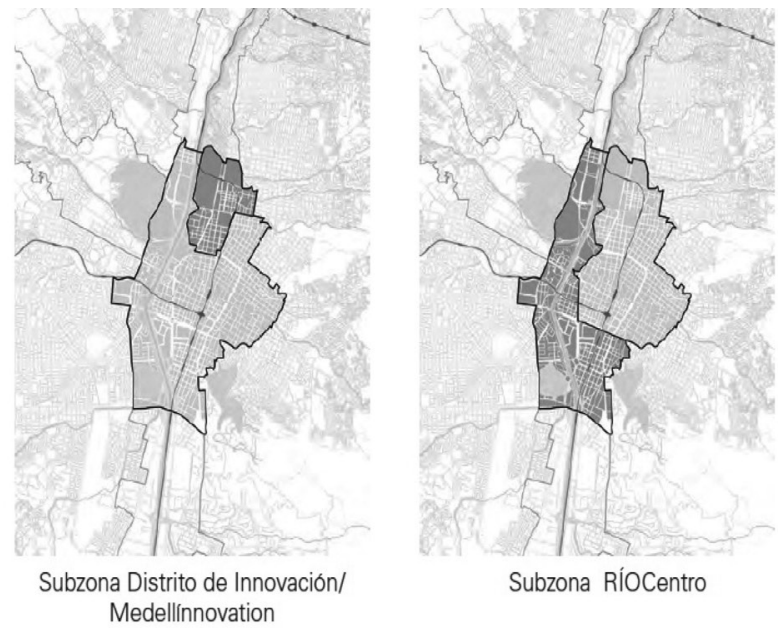

Subzona RíoCentro

Figura 11. Zona de intervención Río Centro, Plan de Ordenamiento Territorial de Medellín

Fuente: Alcaldía de Medellín (2014a, p. 15)

En esta zona céntrica de Medellín, desde el año 2000, se adelantan diversos proyectos a partir de planes parciales, los cuales son retomados por los macroproyectos de intervención trazados en el Decreto 2053 de 2015:

- Plan Parcial de Naranjal y Arrabal, formulado mediante Decreto 1284 de 2000, actualizado y puesto en marcha mediante el Decreto 1309 de 2009.

- Plan Parcial Parque Barrio Colón-San Diego-Palmas, adoptado mediante Decreto 0608 de 2003.

- Plan Parcial Perpetuo Socorro, Decreto 2053 de 2015.

- Plan Parcial Corazón de Jesús, adoptado por Decreto 1316 de 2007.

- Plan Parcial de Guayaquil, adoptado mediante Decreto 1179 de 2007.

- Plan Parcial Plaza Minorista, adoptado y vigente mediante Resolución 227 de 2014.

- Plan Parcial Sevilla, adoptado mediante Decreto 0674 de 2010, actualizado mediante el Decreto 2053 de 
2015. En esta zona, que es contigua al barrio Moravia, se proyecta el Distrito de Innovación.

- Macroproyecto de intervención Urbana en el Barrio Moravia, adoptado mediante Decreto municipal 1598 de 2006, actualizado mediante el Decreto 0321 del 29 de mayo de 2018.

La mayoría de los planes se desarrollan con un tratamiento de renovación urbana, lo que implica transformaciones importantes del espacio construido en esta zona de la ciudad. Las intervenciones proyectadas tienen como fin avanzar en la consolidación de un corredor metropolitano de servicios, como gran centralidad del área metropolitana del valle de Aburrá y cuyo eje económico es la visión de desarrollo competitivo alrededor de clústeres ya definidos (Pineda, 2019).

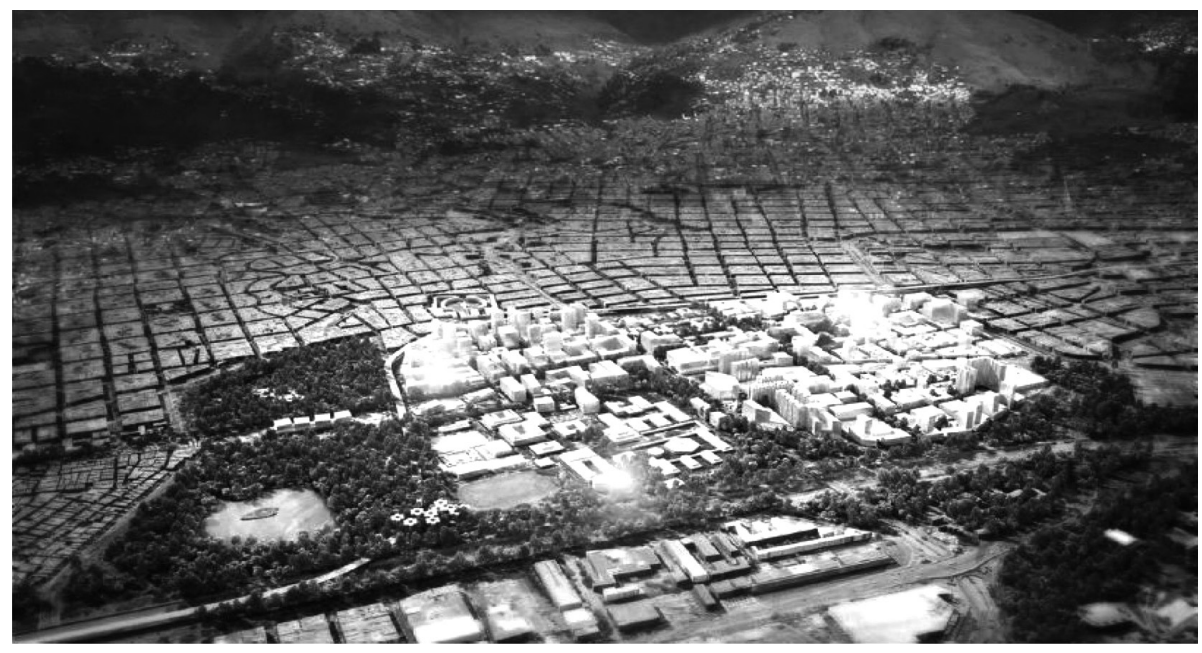

Figura 12. Proyección del Distrito de Innovación, ubicado en proximidad a Moravia

Fuente: Alcaldía de Medellín (2014b, p. 85) 


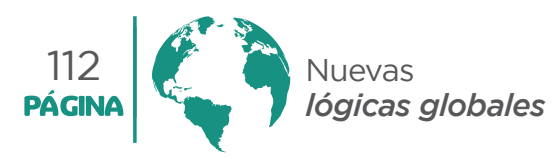

Los elementos expuestos permiten ver que Moravia se encuentra ubicado dentro de un sector estratégico para las intervenciones urbanas en la ciudad con la proyección de ser un centro de atracción de orden metropolitano, lo que genera presiones por los usos actuales y futuros del suelo, especialmente ante la posibilidad de captar mayor renta por estar contiguo a zonas en proceso de valorización. Al analizar los procesos de intervención y las políticas asociadas en la acción del Estado en el barrio Moravia, se reproducen los patrones analizados por Janoschka y Sequera (2014), Fernández (2008) y Britis (2017), donde las intervenciones han apuntado a reubicar -expulsara los habitantes de este lugar céntrico, posicionando procesos económicos y especulativos sobre el suelo que contribuyen a procesos de desarraigo territorial, en los que las acciones institucionales no tienen presente las condiciones territoriales de este sector.

En este sentido, el poder regulador del Estado a través del ordenamiento territorial (OT) está relacionado con el proceso histórico de conquista, apropiación de "vastos espacios" y dominio sobre pobladores, quienes tenían sus propias formas de relacionamiento con el espacio, lo cual ha implicado la creación de fronteras como formas de organización espacial para el establecimiento del "nuevo" orden social y político. Esta forma de planeación estatal "ha sido criticada por su carácter voluntarista, que se expresa en un conjunto de normas, políticas y acciones sobre el espacio y su uso, que han tenido un talante autoritario y muchas veces desconectado de las realidades locales" (Beuf y Rincón, 2017, p. 16). Frente a esta tensión emergente sobre el ordenamiento, entre la disposición de dinámicas sociales y el poder "absoluto" en la normativa, es importante retomar las preguntas planteadas por Beuf y Rincón (2017) al respecto: 
¿Qué es ordenar los territorios? ¿Es producir un conjunto de normas y leyes o es desarrollar acciones reales de transformación de los territorios? ¿Quién tiene capacidad de acción real sobre los territorios y de dónde proviene este poder? ¿Cuáles son los mecanismos concretos que aseguran el despliegue de esta capacidad de transformación territorial? ... ¿Qué se ordena en un territorio? ¿Cómo se ordena? ¿Quién ordena? ¿Para qué se ordena? (pp. 17-24)

Las respuestas a estas preguntas muestran que el diseño de políticas que se superponen a las dinámicas sociales, configuradas como un conjunto de reglas que le dan un poder especial a una institucionalidad, la cual actúa bajo principios de flexibilización y funcionalidad con la reproducción capitalista (Theodore et al., 2009), entra en fricción con formas de apropiación y producción particulares del espacio; en este sentido, el poder estatal estimula la formación de espacios propensos a la gentrificación.

De acuerdo con los elementos reseñados, se observa que con el proceso de renovación urbana definido en el nuevo POT de la ciudad de Medellín y las intervenciones trazadas para el centro ampliado y representativo de la ciudad en su conjunto, se configura un gran proyecto urbanístico donde las diversas obras y planes se entrelazan para transformar un amplio sector de la ciudad.

Estos procesos de intervención urbana apuntan a generar una nueva infraestructura que sea soporte de los procesos de inserción global de la ciudad de Medellín (Pineda, 2019). Sin embargo, generan una fricción por el uso del espacio, una oscilación entre las perspectivas de inserción global, y el espacio de subsistencia y de prácticas de la vida 
cotidiana para un amplio número de familias que, como en el caso de Moravia, se convierte en un espacio permeable, con las características propias para ser gentrificable, por las presiones y las zonas de valorización contiguas, lo que seguramente llevará a la expulsión de sus habitantes tradicionales.

La posibilidad de ocupación y usos y su proyección en las diversas intervenciones desarrolladas durante los últimos 40 años en Moravia, han sido planeadas desde afuera. Incluso, en ellas no se contempla una intervención para modificar los contextos de informalidad económica presentes, por el contrario, históricamente la acción institucional ha provocado procesos de movilización y/o fricción ante las familias. Las propuestas de transformación de Moravia no tienen en cuenta la construcción social y los lazos que existen entre sus habitantes como una construcción histórica. La acción institucional se centra en modificar la infraestructura -viviendas, vías, equipamientos-, situación que situación que termina en una ruptura en las relaciones sociales históricamente construidas y procesos de expulsión territorial, sobre todo cuando la opción detrás de las intervenciones es lograr un mayor uso del suelo, lo que implica cambios que sus habitantes no tienen cómo costear.

\section{Conclusiones}

En el contexto actual de globalización económica, se impone la transformación de amplios sectores de las ciudades, ya sea como soporte de las actividades económicas o como parte del proceso para captar mayor renta (Ruiz, 2016): proyectar un espacio renovado en permanente transformación, tanto en su infraestructura como en los discursos de promoción y los mismos 
imaginarios de ciudad. Esta situación se superpone sobre la dinámica histórica de poblamiento y construcción informal de los territorios, donde prima el valor de uso, las relaciones sociales y construcciones históricas por encima de las condiciones paisajísticas o las características propias de los asentamientos. Esta tensión entre la reproducción del capital y los espacios de la vida social, que se refleja en la política de intervención del Estado para los asentamientos informales, oscila entre recuperar predios ocupados, tratar de brindar condiciones básicas de habitabilidad o promocionar zonas céntricas como atractivos competitivos.

Esta oscilación termina expulsando a aquellos habitantes que sobreviven en condiciones precarias y de informalidad económica y no cuentan con recursos para pagar las nuevas valorizaciones que generan las intervenciones, es decir que se profundiza el carácter gentrificable de estos espacios ante los ritmos e intencionalidades de las valorizaciones centradas en dinámicas de mercado.

La indecisión del Estado en crear una protección integral para los moradores termina siendo la causa de desterritorializaciones por las renovaciones urbanísticas acontecidas. Para el caso de Medellín, por ejemplo, cuando se formuló el acuerdo municipal en este sentido no se contempló la discusión alrededor de la gentrificación ni tampoco se menciona. La fase actual de desarrollo capitalista ha puesto a competir las ciudades, y con ellas sus políticas, por condiciones de inserción en la economía global, lo que ha generado un proceso de privatización urbana en el que las condiciones de vida de los habitantes quedan sometidas a la prosperidad de las actividades económicas privadas, situación que golpea de manera más directa los territorios informales (De Mattos, 2009; Janoschka y Sequera, 2014; Lungo, 2005). 


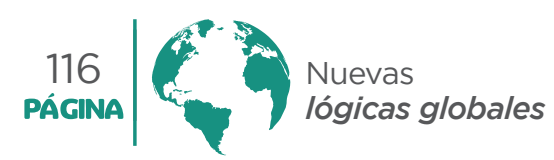

Las formas de poder reflejadas en la acción estatal responden a los principios de flexibilización y urbanismo neoliberal, lo que intensifica la condición de permeabilidad de los territorios y los somete a la volatibilidad del mercado, estímulo para los procesos de gentrificación.

Se ha enfatizado en que la informalidad de los territorios se encuentra vinculada a una informalidad económica, y esto implica, al analizar las intervenciones proyectadas para el centro ampliado y representativo de la ciudad de Medellín, que las expulsiones de amplios sectores estarán asociadas a sus condiciones materiales que no les permitirán residir en los territorios que se transforman, como en el caso de Moravia y los procesos de valorización de los territorios circundantes, y se convierten en territorios con las características para ser gentrificables.

Las políticas estatales, como las aplicadas en el barrio Moravia, van en contravía de los procesos históricos de construcción comunitaria y de sus prácticas, de las formas de apropiación y disfrute colectivo de la ciudad. De esta forma, la ciudad quedaría reducida a quien pueda pagar para habitarla. El derecho a la ciudad debe estar en el centro de la agenda pública y las políticas de intervención urbana; la regularización de amplios sectores de ciudad no puede estar en la vía de legalizar para expulsar, o convertirlos en propensos a procesos de valorización en clave de captación de una mayor renta. 


\section{Referencias}

ACl Medellín - Consorcio UdeA-UPC-CSIC (2007). Recuperación Integral del Morro de Moravia: Restauración y Gestión para la Utilización como Espacio Público. Documento de formulación de proyectos. https:// saladepremsa2. upc. edu /aldia/ mes-noticies/2010/ la- catedra- unesco- desostenibilitat-transforma-un/M3_MORAVIA-UPCUDEA-ACI-AM.pdf

Alcaldía de Medellín, Departamento Administrativo de Planeación. (2006). Plan Parcial de Mejoramiento Integral del Barrio Moravia, 2004-2011. Documento técnico, Tomo I. https:// www.medellin.gov.co/ irj/ go/km/docs/wpccontent/Sites/Subportal\%20 del\%20Ciudadano/Planeaci\%C3\%B 3n\%20 Municipal/Secciones/Informaci\%C3\%B3n\%20 General/Documentos/POT/PPMORAVIA\%20D\%20 TECNICO\%2OCOMPLETO\%2ODEFINITIVO.pdf

Alcaldía de Medellín, Departamento Administrativo de Planeación (s. f). Macroproyectos urbanos. Crecimiento hacia adentro, Macroproyecto Río Centro. [Presentación en Power Point]. https:// www. medellin. gov.co/ irj/go/km/docs/pccdesign/ SubportaldelCiudadano_2/PlandeDesarrollo_0_17/ Programas y Proyectos /Shared\% 20Content/ Documentos/ 2015/ Macroproyectos\% 20 POT/ Taller\% 201\% 20-\% 20 Oficial\% 20R\% C3\% A Do Centro \%20 -\% 2011ago 15\% 20 (DAPM).pdf

Alcaldía de Medellín. (2014a). Cuadernos de ciudad. Áreas de Intervención Estratégica (AIE). Departamento Administrativo de Planeación de Medellín. https:// www. medellin. gov. co/ irj/ go/ km/ 
docs/ pccdesign/ Sub portal del Ciudadano _2/ Plande Desarrollo_0_17/ Publicaciones/ Shared\% 20Content/ Pabellon Medellin/ Cuadernos\% 20de\% 20Ciudad.pdf

Alcaldía de Medellín. (2014b, ). Medellín en proceso / ciudad para la vida. Sociedad, plan y proyectos. VII Foro Internacional de Parques, Bogotá, Colombia. 23 de octubre de 2014. http://www.idrd.gov.co/ sitio/idrd/sites/default/files/imagenes/2014-1022ForodeParques.pdf

Alcaldía de Medellín. (2018). Plan parcial de renovación urbana: Barrio Moravia y su área de influencia. Polígono Z1-R-7. Tomo II, Formulación.

Alzate, G. A. (2014). Intervención urbana en el antiguo Basurero Municipal de Medellín: una respuesta ineficaz al abandono estatal (1977-1986). Estudios Políticos, (44), 191-217.

Brites, W. (2017). La ciudad en la encrucijada neoliberal. Urbanismo mercado-céntrico y desigualdad socioespacial en América Latina. Revista Brasileira de Gestão Urbana, 9(3), 573-586.

Calle, C. (s. f.). Moravia Social Tour. Centro de Medellín [página en internet]. https://www.centrodemedellin. co/ArticulosView.aspx?id=306\&type=A\&idArt=307

Centro Laubach de Educación Popular Básica de Adultas (CLEBA). (1987). Un pasado de basura, un presente de lucha: recuperación de la historia de los barrios Fidel Castro, El Bosque, Moravia, Milán y Los Llanos, sectores del antiguo basurero de Medellín. Revista Educación Popular Básica de Adultos, 5. 
Concejo de Medellín (2015). Macroproyecto Moravia, sesión de seguimiento. [página en internet]. https:// es.slideshare.net/ConcejoMDE/final-moraviaconcejo-2015

De Mattos, C. (2009). Modernización capitalista y revolución urbana en América Latina: cinco tendencias genéricas. En P. Brand (Ed.), La ciudad latinoamericana en el siglo XXI: Globalización, neoliberalismo, planeación (pp. 37-82). Medellín: Universidad Nacional de Colombia.

Díaz, I. (2013). La gentrificación en la cambiante estructura socioespacial de la ciudad. Revista Bibliográfica de Geografía y Ciencias Sociales, XVIII(1030), 42-98.

Fernández, E. (2008). Consideraciones generales sobre las políticas públicas de regularización de asentamientos informales en américa latina. Eure, 34(102), 25-38.

Gonzales, M. (2009). Gestión de los asentamientos informales: Un asunto de Política Pública. (Tesis de maestría, Universidad Nacional de Colombia). http:// www.bdigital.unal.edu.co/691/1/43746388_2009. pdf

González, L. (2011). La experiencia de Desarrollo Urbano de Medellín - Escala Barrial/Comuna (Ponencia, Seminario Informalidad Urbano-Rural - Maestría en Estudios Urbano Regionales). Universidad Nacional de Colombia, Medellín, Colombia.

Hidalgo, R., y Janoschka, M. (Eds.) (2014). La ciudad neoliberal: gentrificación y exclusión en Santiago de Chile, Ciudad de México, Buenos Aires y Madrid. Santiago de Chile: Universidad Autónoma de Madrid. 


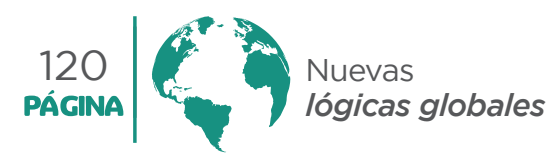

Janoschka, M., y Sequera, J. (2014). Procesos de gentrificación y desplazamiento en América Latina, una perspectiva comparativista. En J. J. Michelini (Ed.), Desafíos metropolitanos. Un diálogo entre Europa y América Latina (pp. 82-104). Madrid: Catarata.

Janoschka, M., y Sequera, J. (2016). Gentrification in Latin America: Addressing the politics and geographies of displacement. Urban Geography, 37(8), 1175-1194.

Lungo, M. (2005). Globalización, grandes proyectos y privatización de la gestión urbana. Revista Urbano, 8(11), 49-58.

Montoya, J., Cuesta, O., Flecha, O., Viadé, D., Gallegos, A., y Morató, J. (2011). Moravia como ejemplo de Transformación de Áreas Urbanas Degradadas: Tecnologías Apropiadas para la Restauración Integral de Cuencas Hidrográficas. NOVA, 9(15), 39-49.

Montoya, J., y Pineda, H. (2018). La gestión social del territorio a partir de intervenciones socioambientales en asentamientos informales: Barrio Moravia en Medellín y Localidad Ciudad Bolívar en Bogotá. En Y. Gómez (Ed.), Observatorio Público. Experiencias, tendencias y desafíos. Líneas de investigación para explorar los campos de las Ciencias Administrativas y de Gestión, Económicas y Contables (pp. 224263). Medellín: Publicar-T.

ONU Hábitat. (s. f.). Viviendas y mejoramiento de asentamientos precarios. https://es.unhabitat.org/ temas-urbanos/viviendas/

Pineda, H. (2019). Clúster, infraestructura y mercadeo de ciudad. Medellín 1995-2013. Bitácora Urbano Territorial, 29(1), 139-146. 
Ruiz, J. R. (2016). Aproximación conceptual a la gentrificación y sus impactos sociales. Ciudades, Estados y Política, 3(1), 49-60.

Sanín, J. D. (2009). Configuraciones del hábitat informal en el sector El Morro del barrio Moravia. Bitácora Urbano Territorial, 2(15), 109-126.

Santana, P. (1986). Mejoramiento barrial: Moravia, Medellín, Colombia. Eschborn, Alemania: Deutsche Gesellschaft Fur Technische Zusammenarbeit.

Theodore, N., Peck, J., y Brenner, N. (2009). Urbanismo neoliberal: la ciudad y el imperio de los mercados. Temas Sociales, 66, 1-12.

Torres, C. A. (Coord.) (2009). Ciudad informal colombiana. Barrios construidos por la gente. Bogotá: Universidad Nacional de Colombia.

Uribe, C. (2010). Dinámica de la relación entre derecho y territorio en el marco de la intervención urbanística del barrio Moravia de Medellín. Diálogos de Derecho y Política, 4(2), 2-33.

Vergara, C. (2013). Gentrificación y renovación urbana. Abordajes conceptuales y expresiones en América Latina. Anales de Geografía, 33(1), 219-234 

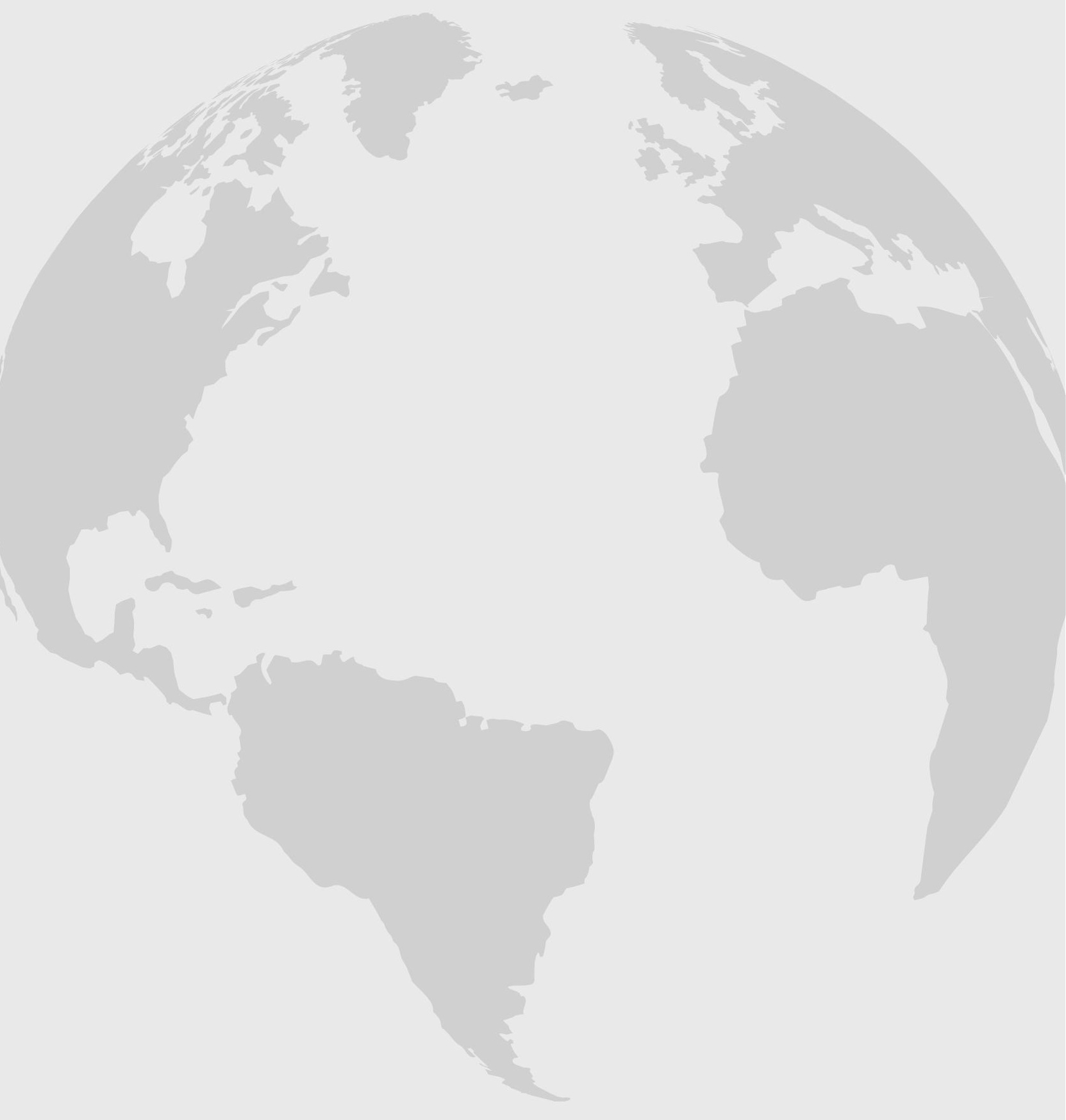